\title{
COMENTARIOS A UN FAMOSO PARECER CONTRA LAS CASAS
}

\author{
Marcel Bataillon \\ (Colegio de Francia)
}

Hay pocos documentos más interesantes para la "historia moral" de las Indias que el llamado "memorial anónimo de Yucay". del 16 de marzo dé 1571 (1). Para desentrañar su sentido, importa mucho conocer la situación personal del autor. Felizmente su anónimo es transparente. Su manera de firmarse "su siervo" y una alusión a "su profesión que es dar luz", hicieron sospechar justificadamente que era director de conciencia del Virrey. Jiménez de la Espada (2) pensó en el Dr. Pedro Gutiérrez, capellán de don Francisco de Toledo en los años de su visita general. Pero la nota humilde de "siervo" (3) unida con cierta manera libre de juzgar a 'los frailes" (4) en general, hacen pensar más que en un seglar, en un religioso que no fuera fraile, es decir en un jesuita. Es curioso que nadieo haya indicadd comolatoroprobable, casi seguro,

(1) Lo cltamos por YUCAY, remitlendo a la primera ediclón Colección de documentos Inéditos para la historia de España, t. XIII, Madrid, 1848, pp. 425-469; Copla de carta que según una nota se hallaba en el Archlvo General de Indlas, y que hemos rectlflcado con otra que tenemos a la vista, donde se trata el verdadero y legítimo dominlo de los Reyes de Espana sobre el Perú, y se Impugna la opinlón del Padre Fr. Bartolomé de Las Casas.

(2) En su edición de Tres relaciones de antigüedades peruanas, Madrid (Ministerlo de Fomento), 1879, p. XXVIII. Equivocadamente habla Lewls Hanke (La lucha por la justicla en la conquista de América, Buenos Alres, 1949, p. 410) del "franciscano Pero Gutlérrez". En la Importante crónlca de D. Francisco de Toledo publicada en D. I. I., t. VIII, p. 245 se le llama "el doctor Pero Gutlérrez Flores su confesor y capellán, del orden y caballerla de Alcántara". Tamblén es equlvocada la interpretación de "otros muchos fralles de todas ordenes" (YUCAY, p. 433) como Indiclo de que fuera fralle el autor: escribe estas palabras refirléndose, no a si mismo, sino al iralle Las Casas.

(3) Lo de "slervo" o "slervo inútll" o "Indigno", o "slervo en Cristo", para cualquler lector de los Monumenta Histórica Socletatis Jesu, suena a Jesulta. Desde luego, lo usaban tamblén los fralles de las ordenes mendicantes.

(4) Véase en partlcular YUCAY, p. 465: "Las pasiones que en estos relnos hay entre rellglosos y estado de legos" ... "toda la multitud de fralles que han seguldo a este hombre" C1. p. 433. 
al Padre Jerónimo Ruiz de Portillo (5), primer provincial de la Compañía en el Perú y director de conciencia del Virrey Toledo en las primeras etapas de su visita.

El Padre Portillo había llegado a Lima en 1568 al frente de la primera misión jesuítica del Perú. Sólo el año siguiente había desembarcado el virrey con un refuerzo de jesuitas. En ellos y en su provincial pensó Toledo encontrar unos auxiliares dóciles para su obra de reforma del gobierno espiritual del país. Pronto había de desengañarse, cuando los jesuitas declinaron las parroquias que les ofrecía y recabaron la originalidad de su instituto. En 1570 todavía dura la luna de miel entre el Virrey y el provincial. Al salir de Lima el Virrey Toledo el 22 de octubre para su famosa visita general, llevó consigo al P. Ruiz Portillo en calidad de confesor y consejero. En la etapa de la Concepción de Xauxa actuó de "Intérprete" de la información virreinal, es decir que le tocó redactar en forma correcta las declaraciones de los indios traducidas "por su lengua" (6).

Pero a la Compañía no le convenía cargar públicamente con la responsabilidad moral de la visita. Los jesuitas del Perú habían solicitado instrucciones de su General sobre compromiso tan espinoso. San Francisco de Borja, al mismo tiempo que agradeció al Virrey el favor con que honraba a sus hermanos, le rogó que le manifestase su amor ayudándoles a respetar su instituto y constituciones. Y escribió el General al P. Portillo: "Lo del visitar o acompañar al Visitador, si se hiciere, no se entremetan los nuestros ên otro sino en nuestros ministerios de predicar, confesar, enseñar la doctrina cristiana, etc. ... Podrá también interceder por los presos y maltratados sin embarazarse en cosa ningu-

(5) No hemos tenldo a mano el llbro del P. Rubén Vargas Ugarte, S. J., Los jesuitas del Perú, Lima, 1941, pero si las Fuentes de la Historia del Perú del mismo autor, $2^{\circledR}$ ed., Lima, 1945, donde (p. 251) hace suya la opinión de Jiménez de la Espada acerca del autor de nuestra Certa. Los libros que utllizamos sobre el P. Rulz Portlllo son el P. A. Astrain, S. J., IIstorio de la Companía de Jesús en la Asistencia de Espana, tomos II y III, Madrid, 1905 y 1800, y la Hlstorla general de la Compańa de Jesús en la Provincla del Perú (Crónlca anónlma de 1600), ed. del P. F. Mateos, S. J., Madrid, 1944, 2 tomos.- Ce. tamblén Roberto Levillier, Don Francisco de Toledo, t. I, Madrid, 1935, pp. 200. 205 y 211, donde el P. Portlllo aparece como uno de los "intérpretes" de la información virrelnal. La crónica antes citada (D. I. I., t. VIII, p. 245) dice terminantemente que el Virrey lleva al P. Portlllo, "emlnentíssima persona, por su confesor". La Historia general (t. III. P. 13), que habla del asunto únlcamente con motivo de la fundación del coleglo cuzquefio, dice que lo "quiso llevar en su companfla para su regalo y consuelo y para fundar en el cuzco algún coleglo".

(6) Historia general, t. II, p. 13 (y t. I. p. 14). Sobre las diflcultades ulterlores con el VIrrey Cf. Astrain, Op. clt., t. II, pp. 313-314, y t. III, pp. 151-176. Para la Intervención del P. Portillo en la información de Jauja, véase el t. II de la cltada obra de Levillier, Don Francisco de Toledo. . . Informaciones, Buenos Alres, 1940, p. 17 y sigs. Por error evidente de la transcripción aparece el Jesulta en todos 10 documentos eomo Goncalo y no Gerónimo Rulz. 
na de jurisdicción" (7). El P. Portillo se libertó cuanto antes de sus delicadas responsabilidades políticas. En Guamanga se despidió del Virrey para adelantársele al Cuzco en compañía de tres hermanos. Los jesuitas llegaron el 12 de enero de 1571 a la capital de los Incas, en que tanto les importaba establecerse. Desde el Cuzco no tardaría el provincial en visitar el ameno valle de Yucay, donde tenían sus quintas de recreo los nuevos dueños del país como las habían tenido los señores de la nobleza incaica. Allí había de fundar algunos años más tarde la casa de convalescencia y recreación de los jesuitas del Cuzco (8). Es, por tanto, muy natural que desde el valle del Yucay, y a 16 de marzo, dirigiese al Virrey el parecer solicitado por él. Toledo había llegado a su vez al Cuzco en febrero, y se preparaba a hacer personalmente la visita del valle de Yucay, asesorándose ya, en asuntos de gobierno espiritual, del Dr. Pero Gutiérrez Flórez, su nuevo confesor y capellán (9). Puestos a elegir entre el ex-confesor Padre Portillo, y el nuevo, Dr. Pero Gutiérrez, se nos impone, como autor del memorial, el primero, el jesuita-, por las razones ya apuntadas y por otras que iremos viendo.

Enfocado correctamente el documento y aclarados en lo que cabe sus antecedentes, se comprende mejor su carácter de contribución complaciente a la campaña emprendida por el Virrey Toledo. No a base de una añeja experiencia personal de las cosas americanas, sino anticipando las conclusiones de la Información recién emprendida, a la cual se refiere repetidas veces, pretende el autor demostrar que los Incas fueron "tiranos modernos", no señores naturales, que antes de ellos no había más que una "behetría" es decir una muchedumbre anórquica de jefes de familia, cada uno señor de su casa; y que por consiguiente el Rey de España, en virtud de la i concesión del Papa Alejandro VI, era no sólo señor supremo, sino único señor legítimo del Perú. El memo. rial, en este sentido, carece de originalidad y de independencia. Es un parecer solicitado, un alegato más que se deriva de la copiosa información virreynal y contribuye a la fundamentación histórico-jurídica de

(7) Cartas del 14 de novlembre de 1570 cltadas por Astrain, op. c1t. t. II, p. 314, que remlte a Regest Borgiae Hisp., 1570-1573 fol. 190. Sorprende la fecha del 14 de novlembre de 1568 que el P. Lopeteguí (El Padre José de Acosta y las Mislones, Madrid, 1942, pág. 107, n. 50) da para dos cartas de Igual contenido, con referencla al registro Hisp. 69, fols. 180 ro -181 vo del Archivo Romano de la Compaña de Jesús. SI es correcta la fecha de Astraln, el P. Portillo se retiró de la visita virrelnal antes de reciblr las mencionadas cartas. Pero blen podía el Provinclal adivinar las Intenclones del General sobre tan delicado asunto. $Y$ no cabe duda de que su compañero el P. Luls López Insistió para que recobrase su libertad.

(8) Historia general, t. II, pp. 29 y 31 . Sobre la amenldad del Valle de Yucay, cf. el Inca Garcilaso de la Vega, Comentarios reales, lib. V, cap. XXVII.

(9) Crónlca citada del Virrey, en D. I. I., t. VIII, pp. 249 y 259. En el Cuzco nombra el Virrey a los "visitadores eclesí́sticos y seculares" necesarlos para la visita. "Y para si ellgló el hacer por su persona la del Valle del Incar (sic), y nombró para las cosas eclesiásticas el doctor Pero Gutlérrez Florez, su confesor y capellán .... 
la tesis oficial, como la Historia Indica de Pedro Sarmiento de Gamboa (10).

El mayor interés de nuestro memorial está en la manera de atacar la tesis contraria como una aberración exclusivamente lascasista. Y es cierto que Las Casas en sus Treinta proposiciones muy jurídicas y en el Tratado comprobatorio, pretendía salvar la legitimidad de los señoríos indígenas, sobreponiéndoles, nada más, el señorío supremo dei Rey de Castilla y León como rey de reyes, o "emperador sobre muchos reyes". Pero es notabilísimo el empeño del autor -llamémosle ya "el P. Portillo" a título de hipótesis (11), - de presentar a Las Casas como fuente única, diabólicamente inspirada, de la corriente pro-indigenista. $Y$ por otra parte, desarrolla una coherente visión providencialista del descubrimiento y conquista de Ámérica, visión que coincide en parte con la del P. Acosta segundo provincial de la Compañía en el Perú. Estos son los aspectos del memorial que nos interesa analizar.

No era la primera vez que un varón religioso, de una orden apostólica, opinaba contra la política indiana del Obispo de Chiapa. Conocidisimo es el parecer anti-lascasista que espontáneamente mandó al Emperador, en 1555, el franciscano Motolinía (12), sobreviviente de los Doce de Fray Martín de Valencia. Con la autoridad que le daban treinta años de protección de los indios de Nueva España, y de estudios de sus tradiciones, testigo además de la transformación del mundo coloníal desde la conquista hasta la estabilización del virreynato, quiso el apóstol veterano contribuir a la pacificación de los espiritus legitimando el hecho consumado de la conquista española. Explicó al Emperador

(10) Véase la ediclón culdada por Angel Rosenblat, Historia de los Incas, 3n ed., Buenos Alres (Emece), 1943, en particular la larga epistola dedicatoria a Felipe II. Iechada "del Cuzco, I de marzo 1572". Las colncidenclas de pensamlento g hasta de expresión con nuestro memorlal se explican perfectamente, pues el documento hubo de pasar por las manos de Barmiento de Gambon, hombre de conflanza del Virrey, encargado por el de ampllar la parecer fuer esbozada en el parecer que estudiamos. Además, es muy probable que dicho la Historia demitido al Rey en 1571 con los primeros 60 testimonlos, como lo fué en 1571 1571 enumera Barmiento con la Información más completa. En carta del 25 de marzo de ia residencla el Virrey las cartas e Informes que manda por el mismo correo, Junto con de sesenta testiobernador Lope Garcla de Castro. Después de referirse a ln informaclón magnr clarlaad de la de mayor edad y más principales entre los Indlos, afiade: "Para tronco destos yng la dicha ynformación mandé sacar la descripción de la descenclencla $y$ es la verdai cierta y autorizarla (el Impreso "autorlzaua") con testlmonio de que esta mano propla de $S_{u}$ Magestad las vanidades que de esto se a dicho, que va con el pllego de yar". Fi cuademillo Magestad, con un cuaderalllo de esta razón que creo V. A. holgara de Yucag. (R. Levilller, Gobernanta ser el parecer fechado nueve dlas antes en el Vallo de

del Perú, t. III, p. 44.)

del Perú:: cuya pur que se publiquen pronto "las comunicaciones de los primeros jesultas Lopetegui (op. clt., p. 425, nóxima en los Monum. Hist. S. J. anunclaba en 1942 el P. tesis o para rectificarla.

(12) Carta de Tlaxcala, 2 de enero de 1555 , pubilcada varlas veces desde mediados del s1glo pasado (dos veces en $D$. I. I.: t. VII, pp. 254-289, g t. X, pp. 175-216). Cltamos por la relmpresión que sirve de apéndice a la última ediclón de Fr. Torlblo de Benavente o Motolinia. Historla de los Indios de la Nueva Espafia, México, 1941, pp, 291-315. 
que cuando Cortés y sus compañeros llegaron al Anáhuac, el dominio de los Aztecas era reciente: había sido ganado, o más bien "usurpado por guerra". Motolinía recalca el contraste entre la civilización de Culhua -o sea tolteca- que trajo a los Chichimectrs y Otomíes salvajes la agricultura del maíz y otras plantas, la cría de las aves domésticas, el arte de edificar, - y la belicosa civilización azteca, manchada por la muchedumbre aterradora de los sacrificios humanos (13). Los Aztecas eran pues, según Motolinía, como los Incas según Portillo, "tiranos modernos", no antiguos y legítimos señores despojados por la conquista.

A la idolatría sangrienta de los últimos dominadores indígenas contraponía el franciscano los primeros éxitos, ya grandiosos en su concepto, de la cristianización de la Nueva España. Y sin negar la codicia imperante entre los encomenderos, o mejor dicho entre sus capataces -estancieros, calpixques y mineros-, afirmaba que existían entre los nuevos dueños del país muchos buenos cristianos, piadosos y limosneros. Estimaba que los indios mejicanos estaban bien tratados y menos cargados de impuestos que los labradores de la Vieja España (14).

Por fin Motolinía, heredero de los sueños apocalípticos que movieron a Fray Martín de Valencia y a sus hermanos (15), estaba convencido de que el Evangelio había de predicarse en todo el Universo antes de la consumación del mundo. El deber del Emperador, según él, era darse prisa para esta gran obra evangélica precursora del juicio final. Tenía que ensanchar los dominios de Cristo en el Nuevo Mundo, usando de la conquista guerrera como medio y preludio de la conquista espiritual, aunque Las Casas pretendió hacer lo contrario en la Verapaz, "echando el carro delante y los bueyes detrás" (16).

Es de otro temple el anti-lascasismo del P. Portillo, jesuita recién venido al Nuevo Mundo, que salió de España un año después de la muerte de Las Casas. Invitado ciapremiantemente a opinar acerca del gran problema acometido por la Información virreynal, o sea la legitimidad del dominio español en el Perú, apoya decididamente la tesis del Virrey. Y da más peso a su parecer confesando que ha sido partícipe del error de Las Casas hasta que en el Perú se desengañó al contaoto de la realidad, gracias sobre todo a la información cuyas primeras etapas acompañó, y en la cual se injerta su parecer como remate de su colaboración personal.a la par que como conclusión anticipada.

Esta rectificación tiene el carácter de una conversión: "Yo fuí, confiesa hablando de Las Casas, de los que más le creí, y que más mal me parecía quitarle a estos Incas su dominio, hasta que en el Perú ví

(13) Motolinia, ed. cit., pp. 291-292.

(14) Ibid., pp. 292-293, 299, 305 y 307.

(15) Sobre cste aspecto de la conquista espiritual, llustrado por la Vida de Fr. Martín de Valencia escrita por su compañero Fr. Francisco Jiménez (ed. Atanasio López, O. F. M., en Archivo Ibero-Americano, julio-agosto de 1926, pp. 48-83), véaso el resumen del curso de M. Bataillon, L'esprit des évangelis ateurs du mexique, en Anuarle du College de France, 50 e année, París, 1950, pp. 229-230.

(16) Motolluía, ed. cit., pp. 300 y 397. 
lo contrario con otras grandes ceguedades" (17). Por fin recobra la vista. Comprende cómo se dejó engañar por la inmensa autoridad moral de aquel "muy buen religioso" y venerable obispo que durante tantos años impuso sus falsos conceptos a los gobernantes. La clave del misterio es que el propio Las Casas estaba engañado por el demonio, el cual se aprovechaba de sus virtudes y de sus defectos para, con su prestigio de fraile y de obispo, engañar al mundo entero. El error gigantesco en que cayeron el Emperador, su Consejo, sus virreyes y gobernadores, sus audiencias, sus teólogos, catedráticos y predicadores, fué "creer a un hombre solo, que no era razón, por ser uno". Con este éxito prolongado del demonio, felizmente desbaratado por las iniciativas dei virrey Toledo, sólo puede compararse el que consistió en sumir la pobiación toda del nuevo mundo en la idolatría durante tantos siglos, hasta la llegada de los españoles. (18)

Ante esta explicación simplista de la historia, duda el lector moderno si el P. Portillo creía ingenuamente en tanto poder del diabio o si escribía movido por un instintivo maquiavelismo espiritual. Tendría de lo uno y de lo otro. El provincial fué muy combatido por sus hermanos, y entre las torpezas que le achacaron, una fué la de actuar como exorcista en un asunto de mujer posesa. (19) Aquí lo tenemos exorcizando al demonio urdidor de la maraña del lascasismo. Pero también es obvio el provecho político de la operación. Llevado por las circunstancias a apoyar la acción del virrey Toledo, en franca reacción contra la política indiana seguida durante los treinta años anteriores, Portillo le brinda una explicación sobrenatural de esta política desastrosa, explicación que tiene la ventaja práctica de cargar toda la responsabilidad humana del colosal engaño $a$ an solo hombre $y$ a un muerto: Las Casas, instrumento del demonio. Por si quedan en el Consejo de Indias unos letrados o teólogos, en el Perú unos frailes dominicos, todavía persuadidos del derecho natural de las soberanías indígenas, ya queda puesto en evidencia el origen diabólico de su error, y por quien también participó de él: por un lascasista arrepentido.

No puede decirse que Portillo fuera, antes de salir de España, un iascasista de buena ley. Le faltaba para ello la fé en la conquista evan. gélica. Cuando se trataba de mandar jesuitas a la Florida, tierra de misión regada por la sangre del $\mathrm{P}$. Cáncer, mártir de la predicación.del evangelio sin apoyo de las armas, Portillo aconsejó más bien el estabiecimiento de una misión en Honduras, que pudiera ser punto de partida para aicanzar a la China y al Japón ya visitados por San Francisco Xavier. Pero desaconsejó formalmente toda misión a la Florida hasta que estuviese "de paz y bien pacificada", "pues los nuestros, decía, no

(17) YTCAY, p. 433. Tal confesión, natural de un jesulta (Cf. Infra, 12. 47), sería sorprcuderse en eí Dr. Pero Gutiérrez, personaje que el Virrey "Conslgo de Espana con licencla del Rey . . habia trá́do". No habría escogldo el virrey a un lascasista para llevárselo al Perú.

(18) YUCAY, p. 426.

(19) Artrain, op. cit., p. 152. Es interesante cotejar este caso con otro en que anduvo Canislo por los mismos años, sacando la conclusión de que a los jesuitas les convenfa rechazar el papel de exorcistas (Canisii Epistulae et Acta, t. VI, Frelburg I. Br, 1913, pp 398-401, Carta de Canlsio a S. Francisco de Borja, Augsburgo, 8 de abrll de 1570). 
van a conquistar, sino a evangelizar" (20). Tal fórmula pugna diametralmente con el ideal misionero de Las Casas y de Zumárraga que quisieron sustituir la destructora conquista militar por "la conquista de las almas". (21) Y cuando llega a América el prudente jesuita, absuelve con toda indulgencia (22) a los conquistadores que fueron matadores de buena fe: ya porque se imponía el terror a un puñado de hombres como método para domeñar pueblos innumerables, ya porque la idolatría les parecía crimen digno de la muerte.

Pero a pesar de todo esto, era muy natural que el ex-obispo de Chiapa mereciera la admiración de Portillo, superior del noviciado de Simancas, cuando los jesuitas españoles eran amigos de los dominicos espirituales, y en particular de los de San Gregorio de Valladolid, desde donde Las Casas ejercía su influencia de Procurador de los Indios. (23) Es interesante nuestro memorial como retrato del personaje histórico de Las Casas tal como lo veían los frailes y jesuitas enterados de la política indiana de Carlos V y de Felipe II. Aparece aquí estilizada y falseada por la versión de Gómara la empresa del clérigo a la costa de Cumaná con trescientos labradores. Lo que más resalta es la actuación

(20) Monum. Hist. S. J., Borgia, t. IV. pp. 486-487 y 496. Cartas del P. Jerónlmo Rulz del Portlllo a S. Francisco de Borja. Sevilla, 26 de Junlo y 14 de jullo de 1567. Cf. Fèllx Zubillaga, S. J., La Florida, la misión Jesuitica (1566-1572) y la colonización española, Roma, 1041. Esta concepción prudente estaba de acuerdo con la del General. San Francisco do Borja, cuya Instrucción para el $P$. Portillo y sus hermanos decía: "No se pongan fácllmente on pellgro notable de vida entre gente no conquistada, porque aunque sea provechoso para ellos el morlr en esta demanda del divino servicio muy presto, no sería útil para el blen común" (Astrain, op. clt., t. II, pp. 306-307).

(21) Sobre el Ideal de la conquista pacifica por los evangelizadores, ideal estrechamente ligado con el respeto de las soberanias Indigenas, cf. Lewis Hanke, op. cit., pp. 184-205, y sobre todo Juan Manzano, La incorporación de las Indias a la Corona de Castilla, Madrid, 1048, pp. 01-217. Estudiamos el tema en el ya cltado curso del Coleglo de Francia (Anuaire..., 1050, pp. 232-233) y en un articulo del Bulletín Iispánique de 1951 (La Vera Paz, Roman ct histoire.

(22) Véase YUCAY, p. 440.- Pensamos en una absolución moral, no sacramental, pues tamblén sobre este punto los jesuitas del Perú iban prevenidos por su General para no meterse "en absolver $n l$ en condenar a los prlmeros conquistadores" (Borgla, t. IV, p. 514, Borja a Portlllo, Roma 13 de agosto de 1567. Cf. Ibld... p. 652, la carta del 3 de octubre de 1568 en que el General se alegra de que los jesuitas entren en el Perú después de zanjadas por el sínodo de los oblspos "las dificultades en las materias de las restricciones y absoluclones...")

(23) Para la etapa de Simancas del P. Portlllo, (Jesuita desde 1553 según Sommervogel, Blblloteca de la Compañia de Jesús, t. VII, col. 324) cf. sus cartas de 1555 al P. Araoz y a San Ignaclo (Cartas de San Ignacio de Loyola, t. V, Madrld, 1889, pp. 432-436, y Epistolae mlxtaer-(Monum. Hist. S. J.), t. IV, pp. 823-825). Es estrecha en aquellos anos la amlstad de Fr. Luis de Granada, O. P., con los Jesultas de Evora. Y otro hljo de San Gregorio, el Arzoblspo Carranza, fué amigo de la Compañia. Es poslble que clrculara en San Gregorio y en Simancas la extensa carta de Bartolomé de Las Casas al P. Carranza de Miranda (entonces en Inglaterra con el prínclpe) de agosto de 1555, documento capltal para el desarrollo de la doctrina de Las Casas, sobre la "honorifica dignidad real, y quasi como imperlal" de los Reyes de Castilla "de ser sobre muchos reyes soberanos princlpes". Alli examina Las Casas la posibllidad de que los Reyes de las Indlas. después de sujetarse voluntarlamente al rey de Castllla y al yugo de Cristo, "quieran traspasar en los reyes de Crstilla el derecho y señorio que tienen sobre las minas de oro y plata, perlas y pledras, y las sallnas, que son suyos proplos". (Apéndlce XXVIII de la Vida de Las Casas de Fablé, en Col. de doc. Inéd. para la hist. de España, t. LXXI, pp. 410-411 y 417). 
del fraile en la Corte entre 1540 y 1543 . También estilizada y con notoria exageración del influjo de Lqs Casas. Llega de América, "sin licencía de sus prelados $(24)$, y preguntándole después que con qué licencia vino, réspondió que con la de la caridad". Tiene la suerte de que el franciscano Fr. Jacobo de Tastera, gran fraile de Indias, acaba de denunciar al Emperador muchos errores de las conquistas y le lleva al soberano para que confirme la destrucción de las Indias. La elocuencia de Las Casas hace mella en Carlos V. De allí resulta la visita del Consejo de Indias, con la destitución de dos oidores. El Presidente -el Arzobispo Loayza se va a su diócesis de Sevilla, y le sustituye otro, o sea Ramírez de Fuenleal. (25) La victoria de Las Casas es tan completa que maneja el Consejo de Indias. Pronto se acrecienta su prestigio con la dignidad de Obispo. Ya no se nombra virrey, oidor ni obispo que no sea de la opinión de Las Casas.

Otro resultado de su influencia es la promulgación de las Leyes Nuevas; y en lo que atañe al Perú, el nombramiento de Blasco Núñez como virrey, después de resistir más de seis meses aquel infeliz que presentía su trágico destino. Las Casas persuadió a toda España, desde el Emperador y Consejo hasta los menores frailecitos de allá", que los legítimos señores del Perú eran los Incas, con sus caciques y curacas.

La conclusión lógica fué persuadir al Emperador que la única salida del avispero peruano era dejar estos reinos a los Incas tiranos. Hubo de oponerse a esta locura Vitoria, quien opinó en pro de la ocupación española hasta que los indios fuesen capaces de perseverar en la fe católica. (26)

(24) En realidad, llega recomendado por todos los preludos como "curta viva" de lon gobernantes espirituales de América, según frase dél Oblspo des Guatemala Marroquín (cf. M. Batallion, La Vera Paz... art. cit.)

(25) Ha sido confirmada por los trabajos de Schaefer, el Consejo Real y supremo do las Indias, t. I, Sevilla 1935, pp. 5I-70, la visita del Consejo de Indlas pero no que fuera Las Cala segunda unico instigador de ella. El crédito del Obispo Ramírez de Fuenleal (presidente de de Las Casas en los asuntos de Indlas es muy anterior a la intervención bramiento de Ramia Corte. Si valen estas simplificaciones, no se debe a Las Casas el cncumcumbramiento, para un oblspado yamiento lóglco de su actuación, hace posible la elección de Las Casas conquistas (cr. y su admision temporal en el Consejo para la orlentación nueva de las conquistas (cr. Nanzano, op. cit. pp. 135-136, y Batallon, La Vera Paz, art. cit.)

(26) YUCAY, pp. 426-429 y 443. La última afirmación de que, por influjo del P. Lis Casas, "quiso S. M. dejar estos reinos a los Ingas tiranos, hasta que Fl. Francisco de Vitoéstos fuesen capaces dejase, que se perdería la cristiandad, y prometió dejarlos cuando éstos fuesen capaces de conservarse en la ié católica" es probablemente la más forzada y arbitrarla de todo el memorial. El Prop. Juan Manzano fundó sobre ella unas páginas tituladas "El Emperador dispuesto a sbandonar las Indias" (op. clt., pp. 124-134; cf. el indice p. 355). Aunque se sume a la autoridnd de Portlllo la de Saimiento de Gamboa (1bid., p. 127), la del licenclado Falcón (ibld., n. 128) y la de Lope García de Castro (Ibld., p. 129), hay el rlesgo de que las cuatro se reduzcan a una, y que todo salga de un recuerdo amanado o falso del P. Portillo. Llama la atención el hecho de que una novedad relativa a la nolítica Imperial de Carlos $V$ en 1542 esté atestlguada únlcamente por cuatro afirmaciones salldas del Perú unos trelnta años despues, es declr, cuando el P. Portlllo está allí. No da Manzano la fecha de la Memolia de García de Castro, pero sabemos que Portillo le 
Si prescindimos del último punto, tenemos una estilización del papel histórico de Las Casas que pudiera desarrollarse en biografía hagiográfica: espléndido papel de predestinado, que, inspirado por Dios, cambia el rumbo de la historia, y gracias al cual el corazón del Rey, está, según la Biblia, en la mano de Dios. Sustituido Dios por el demonio, vuelta la hagiografía del revés, la historia viene a ser un drama de títeres en que Las Casas actúa de protagonista omnipresente con su demonio familiar al lado, Vitoria de Deus ex machina que salva el imperio en el borde del abismo, y el Virrey Toledo de arcángel mandado por Dios para vencer al demonio definitivamente. El esquema de Portillo coincide en muchos puntos con la realidad concreta. Es falso por hacer de "un hombre solo" el motor único de amplios acontecimientos. Es cierto que deja vislumbrar un mundo complejo de frailes apostólicos en lucha contra los seglares, de oidores, obispos, gobernadores y virreyes que "son de la opinión de Las Casas", es decir la realidad que revela cada vez mejor la investigación histórica. Pero le conviene, para despejar el terreno ante los pasos del Virrey, que aquel mundo tan pletórico de fuerzas espirituales carezca de vida propia, o padezca una desorientación general, que alcanza hasta el Rey, por los pecados de Las Casas juguete del demonio.

El último maleficio de Las Casas y del diablo su inspirador es la impresión de sus tratados, unos atestados de horrores auténticos o fabulosos de la conquista española, otros, llenos de la dañina doctrina de la soberanía indígena. Y con esto llegamos al meollo de la significación histórica del parecer de Portillo. También se quejaba Motolinía en 1555, de los vituperios de Las Casas contra sus compatriotas, ya en el Octavo remedio ya en el Tratado de los indios hechos esclavos; reprobaba el franciscano estos escritos como libelos infamatorios contra los Españoles de Nueva España (27). Pero el memorial de 1571 va más lejos. Aunque no se publicó aún por entonces ninguna traducción extranjera de la Brevísima relación de la destrucción de las Indias, le consta al jesuita que corren los libros de Las Casas "hasta las manos de las naciones enemigas de la Iglesia", turcos y herejes, sirviendo de base a truculentas acusaciones contra los campeones de la fe. (28).

Portillo que tenía razones personales de conocer la lucha sostenida por el Adelantado de la Florida contra los hugonotes de Ribaut (29), señala el peligro de que los príncipes cristianos se atreven a pre-

alcanzó en Lima (YUCAY p. 461). En cuanto a Sarmlento de Gamboa, ya notamos (supran. 10) la probabilidad de que utllizara nuestro memorial en el Cuzco. El texto del licenclado Falcón es aủn más tardío: fué presentado al tercer Concilio limeño (1582-1583), y tamblén puede tener a Portillo por fuente directa e Indirecta.

(27) Motolinia, op. cit., p. 305 y sigs. No parece que Motolinia leyese por entonces la Brevísima relación de la destrucción de las Indias. En la p. 294 se refiere a los "conflsionarios impresos", o sea a los "Avisos para los confesores de los espafioles en cargo a los indios" y de este confesonario salen cvidentemente las frases criticadas por Motolinia (pp. 295, 299 y 300 ).

(28) YUCAY, p. 439.

(29) Cf. supra, n. 20. 
tender estas Indias o parte de ellas contra su Santidad, diciendo que lo hicieran mejor que los españoles. Como al conjuro del endemoniado Las Casas, hierve el mar caribe de herejes luteranos, ingleses y franceses (30).

España llega al apogeo de su poder hegemónico y ya lo siente amenazado por la incipiente "leyenda negra" y por posibles talasocracias rivales. Entonces es cuando Portillo formula un concepto de la conquista de América bastante distinto del de la gran generación evangelizadora de Motolinía, Zumárraga y Las Casas: un concepto encajado ya en la mentalidad de cruzada de la Contrarreforma. Portillo escribe unos meses antes de la victoria de Lepanto. Escribe en Yucay como jesuita enterado, desde Roma, de los preparativos de la Santa Liga entre el Papa y Felipe II. En esta coyuntura se le hace patente la justificación de la conquista del Perú: "porque si bien se mira, después que estos reinos del Perú se ganaron, hasta hoy, que son casi cuarenta años, no se ha visto ni se ha podido alcanzar la justificación de la labor de estas mi. nas de oro y plata y azogue, que es increíble si no se vé, hasta estos tiempos, cuando el Rey se determinó a esta Santa Liga (31).

Ahora cuaja una filosofía de la conquista que viene esbozándose desde las bulas alejandrinas, desde la época en que las Indias se reducían a unas islas. Dios había dado las Indias a España en premio a los trabajos de la Reconquista, a los ocho siglos de guerras que fueron necesarios para arrancar a la morisma lo que había ganado en ocho meses. No sin misterio coincidía la toma de Granada con el descubrimiento de Colón (32). Pero se fija el jesuita en otros aspectos providenciales del gran negocio de las Indias. Se las da Dios a España por el más alto título posible, ño por guerra de conquista, sino por donación del Papa, de modo que Dios mismo, por vía pacífica, ensancha la cristiandad. Se las da limpias de polvo y paja "sinerepartir con otros Reyes y señores", sin quedar en ellas rastro de soberanía indígena, así como se conquistó el reino de Granada sin quedar en él ningún rey moro (33). I es de ver cómo resuelve el P. Portillo la contradicción aparente entre la existencia del imperio incaico y la afirmación de que los españoies encontraron este Nuevo Mundo como res nullius, cosa sin duedel Virrey) Los Incas son tiranos ilegítimos. Pero es otro misterio providen-
cial que hayan conquistado los reinos del Perú por guerras, de manera

(30) YUCAY, pp. 443-444.

(31) Ibld., p. 460

(32) Ibid.,pp. 429-431. Sohre ei slgnificado político de las bulas alejandrinas, cf. Manuel Giménez Fernández. Las Bulas alejūncirinas de 1493 referentes a las Indias, Sevilla. 1944: palense, año VIII, núm. 3,1945); (33) YUCAY, p. 430. 
que, cuando venga la conquista española, los halle "a todos sujetos, aunque tiránicamente" (34).

Asi se cierra en sistema colonial el sueño de imperio universal que en la época de Carlos V. Vitoria y Las Casas consideraban abierto, hospitalario a los señoríos indígenas (35). El jesuita, como ya vimos, integra en este sistema las deslumbrantes riquezas del subsuelo peruano. Las pone incondicionalmente al servicio de la hegemonía española en el viejo mundo (36). Otra vez convergen misteriosamente los acontecimientos de Europa y América. Mientras en Roma y Madrid el Papa y Felipe II andan "en esta divina trama" de la Liga contra el Turco, el Virrey Toledo y el Licenciado García de Castro juntan en el Perú a la flor de los juristas y teólogos, los cuales, nemine discrepante, se pronuncian por la explotación de las minas de donde se sacará tanto oro y plata que sobre para la guerra contra el Turco y baste para hacer grandes mercedes a los reinos peruanos (37).

Ya queda patente la causa final del descubrimiento del Perú. Queda desbaratado el ardid del demonio que persuade a los indios que escondan las minas y tesoros, diciéndoles que, no habiendo minas, luego se irán los españoles y volverán los peruanos a sus idolatrías. Se deshace otro engaño del P. Las Casas, inconsciente auxiliar del diablo, pues amenazaba con el infierno a los españoles codiciosos de tesoros, sin ver que tesoros y codicia entran en el plan de la Providencia para la salvación de los indios. Donde hay tesoros "va el Evangelio volando y en competencia" (38).

El P. Portillo acude a una graciosa parábola para justificar -el papel subalterno que concede en su visión universalista a las Indias y a sus tesoros. Según Las Casas, impertérrito apologista de los indios, los Europeos, antes dela cristianización eran tan bárbaros y viciosos como los indios al llegar los españoles (39). Según el jesuita asesor espiritual del Virrey, Dios se porta con la humanidad de ambos mundos como un padre que tiene dos hijas: la una hermosa y discreta, "la otra

(34) Ibid., pp. 430-431.

(35) Manzano, op. cit., pj. 143 y sigs.

(36) Cr. supra, n. 31, y n. 23; donde se ve la muy diferente doctrina de Las Casas.

(37) YUCAY, p. 461.

(38) Ibid., p. 463. Cf. p. 468-469 donde muestra que destruir la Idolatria de las huacas y abrirlas para sacar los tesoros son procesos colncidentes. El Apóstol de Andalucia, Maestro Juan de Avila, veía señal de la proximidad del juicio final en la "promulgación muy nueva y notable de nuestra Santa fé en las Indias Orientales y Occidentales"; se fljaba también en el movimiento simultáneo de los evangelistas y de los que "van y navegan con viento de la codicla que los haze volar y que todo trabajo parezca allvio": ". . . parece que por via de unos y otros se trata el negocio con mucha prisa, y que es un grande testimonio del breve cumplimiento de la dicha palabra (Mat., XXIV, 14), y por consigulente de la venida del señor a Juzgar" (Memorlal segundo para el Concilio de Trento, 1561, en Misceláner Comillus, Comillas, 1945: Dos memoriales inéditos del Beato Juan de Avila para el Concilio de Trento, pp. 85-86).

(39) Para demostrarlo multiplica en la Apologética historia de las Indias los capitulos sobre la antigliedad. cuya sustancia saca de la Cindad de Dios de San Agustín, y que a algunos lectores de hoy parecen digresiones, aunque no lo son. 
muy fea, legañosa, tonta y bestial". La primera no necesita dote para casarse, "sino ponerla en palacio para que acudan los pretendientes". "Pero la fea, torpe, necia, desgraciada, no basta eso, sino darle gran dote, muchas joyas, ropas ricas, suntuosas casas, y con todo ese Dios y ayuda (40)".

La hija hermosa es la humanidad del viejo mundo, Europa y Asia, cuyos infieles, adornados con todas las gracias del cuerpo y el espíritu, atrajeron primero a los Apóstoles. La hija fea es la indiada bárbara y viciosa, que nadie viniera a cristianizar si no fuera por el oro y plata de sus montañas, o por sus tierras fértiles y deliciosas.

No se crea que esta metáfora sea creación ex nihilo del magín del P. Portillo. Sería interesante seguir su historia desde los sueños nocturnos de Fray Martín de Valencia (41), que, decepcionado por la nueva cristiandad mexicana, quiso hacia 1530 salir en busca de gentes de "tanta razón y policía" como los asiáticos (42) . . . hasta las grandes síntesis del P. Sahagun (43) y del P. Acosta, inmediato sucesor de Portillo como provincial de los jesuitas del Perúi Acosta expone un esquema providencialista de la conquista espiritual del Nuevo Mundo que guarda estrechas analogías con el de Portillo. Escribe cuando, por la unión de Portugal con España, Dios exalta todaría más la misión de la península, pues con las coronas, según dice, "se han juntado también la India Oriental con la occidental dando cerco al mundo con su poder" (44). En los amplios capítulos que dedica a los metales preciosos del Nuevo Mundo, y especialmente de Potosí (45), adopta en lo esencial la explicación del P. Portillo, aunque, más discreto, recalca menos la fealdad de la hija fea. Al résumir esta parábola, no nombra al autor con todas sus letras: se refiere a él como a "un hombre sabio" (46).

Este elogio que respeta el anónimo dernuestro memorial, nos recuerda oportunamente que el $\mathrm{P}$. Portillo fué blanco de las más severas críticas de sus hermanos, especialmente por su actitud frente al virrey.

(40) YUCAT, p. 462.

(41) Sueños referldos en su blografía por un compañero suyo (c1, supra, n. 15).

(42) Proyecto recordado por Zumáriaga y Betanzos en su carta al Principe don Felipe a propóslto de su proyectada conquista pacífica por el Mar del Sur, empresa sobre la cual derrama nueva luz el citado libro de Manzano, pp. 137-147. Puede leerse la aludida carta en J. García Icazbalceta, don Fray Juan de Zumárraga, 3a ed. por Rafael Aguayo Spencer y Antonto Castro Leal, Méxío, 1947, t. III, p. 244, 6 en D. I. I., t. XIII, pp. 531 y sigs.

(43) Fr. Bernardino de Sahagún, Historia general de las cosas de Nueva España, fin del cap. XII y cap. XIII del llbro XI (en. Miguel Acosta Salgnes, México, 1946, t. II, pp. 484-491). donde expone su idea de la "peregrinación de la cristiandad" (páginas escritas en 1576).

(44) Historla natural y moral de las Indias, Sevilla, 1590, llb. IV, cap. VII (citamos por la relmpresión de Madrld, 1894. t. I, p. 3161 .

(45) Lib. IV, cap. LL - XIII.

(46) Lib. IV, cap. II (ed. cit. n. 291): "cerca de esto decia un hombre sabio que lo que hace un padre con una hija fea para casarla, que es darle mucha dote, eso habia hecho Dios con aquella tierra tan trabalosa, de darle mucha riqueza de minas, para que. con ste medio hallase quien la quislese". 
hasta que vino el P. Plaza como visitador y sustituyó en su lugar al P. Acosta como provincial. Sería equivocado hacer del P. Portillo, sabio jesuita político y de gobierno, el perfecto representante de la Compañía en el Perú. Mientras el provincial extrema el antilascasismo para ponerse a tono con el Virrey Toledo, lo que hacen varios hermanos suyos es recoger la lección de Las Casas en la medida que permiten los tiempos nuevos (47). Entre ellos brota otra vez el ideal de la conquista pacífica por la predicación del evangelio (48): de este modo nacen de la provincia peruana las famosas misiones del Paraguay. Incluso, en materia de política indiana, censuran más o menos abiertamente la ejecución de Tupac Amaru (49). El P. Luis López acérrimo adversario del P. Portillo llega a ser encarcelado y perseguido, más que por solicitante (50), por crítico desenfadado de la política indiana del Virrey Toledo (51). Las conclusiones del P. Acosta, en su Historia natural y moral de las Indias ,son una síntesis de la concepción expuesta por Portillo y de la doctrina de los evangelistas defensores de los indios. Sin meterse en demostrar que los Incas fueron tiranos, insiste mucho sobre

(47) Cf. el prólogo del P. Mateos, S. J., a la Historia general citada (supra, n. 5) t. I., p. 11, y su nota del t. II. pp. 18-19, donde considera no sólo al P. Luls López, sino también al P. Bartolomé Hernández y al P. Plaza como "fuertemente influidos por la escuela dominicana de Las Casas y Vitoria".

(48) A fínes del sigio el domínico Fr. Reginaldo de Lizảrraga se refiere a los misioneros Jesuitas, "grandes siervos de Dios, muy consignados a su servicio, para predicar la ley evangélica sólo con las armas de la fe" (Descripción breve de toda la tlerra del Perú, en Fistorladores de Indias, t. II, N. B. A. E., t. XV, p. 508) a estos naturales y con ánimos de entrar por la tierra de guerra a predicar la ley evangélica sólo con las armas de la fe. Cr. la cuestión propuesta en 1578 por el P. Plaza al P. Acosta y a sus consultores, "sl converná que alguno (slc) de los Nuestros entren a predicar el Evangelio en algunas provincias de este relno sin compañia de soldados como entró el $P$. Acosta el $P$. franciscano en el Japón". La contestación fué fávorable, con la advertencía de que "en este Relno se pueden hacer estas misiones comenzando por las tierras sublectas confines a los gentiles" (Lopetegui, op. cit. p. 238). En términos casi idénticos describe Las Casas lo que los dominicos hicieron en la Vera Paz (cf. Batallion, art. cit.).

(49) Acosta, op. cit., lib. VI, cap. XXIII (ed. cit., pp. 210-211), dice que le "dieron la muerte en la plaza del Cuzco, con increible dolor de los indios, viendo hacer públicamente justicla del que tenía por su señor".- La Crónlca de 1600 (Historía general, t. II, p. 25) hace un relato edfficante de la muerte del Inca Túpac Amaru, "industriado" en la fe cristiana por los jesuitas y bautizado. Antes del suplicio dirige el Inca a los indios un verdadero sermón a favor del Dios único, criador e invisible, "que era el que predicaban los Padres de la Compañia". "Quedaron los yndios desde entonces muy devotos y aficionados a los Nuestros, y especialmente los Ingas". Baltasar de Ocampo, que, Informado por los Padres de la Merced, les atribuye la catequización del Inca, menciona sin embargo al P. Barzana, ex-discípulo de Juan de Avila y auténtíco apóstol jesuíta, entre los religiosos que asisten al Inca antes del suplicio (a falta de texto español de Ocampo publicado por Jiménez de la Espada en Relaciones geográficas de Indias, t. IV, Madrid, 1897, véase la traducción inglesa publicada por C. Markham en apéndice a Sarmiento de Gamboa, History of the Incas; Cambridge, 1907 (Hakluyt Soclety, II serles, t. XXII), p. 29). El P. López, S. J., figura entre los prelados de las órdenes que van con el Obispo de Popayán a pedir al Virrey el indulto del Inca.

(50) Sobre este aspecto de su proceso, cf. J. Toriblo Medina, Historia del Tribunal del Santo Oficio de la Inquisición de Lima, 1569-1820, Santiago de Chlle, 1887, t. I, pp. 58 y sigs.

(51) El extracto de sus papeles con la contestación del Virrey (1579-1580) ha sido publlcado en la Col. de doc. Inéd. para la hist. de España, t. CXIV, pp. 471-525. 
la misión providencial que cumplieron el imperio de los incas $y$ el de los aztecas como preparación de América al cristianismo (52). Y aunque se explaya largamente sobre las artes del demonio en estos dos imperios (53), aunque opina que el progreso de la cristianización requiere al mismo tiempo más autoridad y más humanidad con los indios (54), no se le ocurre censurar la política americana de la época de Carlos V como victoria del diablo y de Las Casas.

Hay que pasar por alto, en nuestro memorial, los excesos algo ingenuos de su antilascasismo y de su anti-indigenismo si queremos captar su amplia significación histórica.

La continuidad que hay entre su filosofía de la conquista y la del P. Acosta pone de relieve al inevitable ocaso de la política indiana de Las Casas en el momento en que el Código Ovandino recoge del lascasismo lo que puede salvarse. Peter Rassow (55) mostró lumino- ( samente como el Emperador transformó sin quererlo un viejo sueño medieval de imperio universal en la moderna realidad del imperio es-l pañol.

Al amparo del sueño imperial pudieron Las Casas y sus amigos del Consejo de Indias soñar con un poder imperial del Rey de Castilla sobre muchos reyes en las Indias ya descubiertas y por descubrir. Sueño de respeto a las soberanías indígenas que libremente aceptasen el imperio español y la fé, legitimándose entonces el traspaso a España de las riquezas metálicas de las Indias.

El oro que los primeros evangelistas miraban con desvío, considerando todavía Quiroga y Motolinía que por su falta de codicia podían los indios formar una nueva cristiandad mejor que la de Europa, ya es, con la plata del Potosi nervio imprescindible del poder español. No lo pierde de vista Las Casas, Yi Carlos V bien puede pensar en bases nuevas para su traspaso, no puede pensar en abandonarlo. El oro y la plata de las Indias contribuyen mucho a la metamorfosis señalada por Rassow, y que iniciada en las postrimerías de Carlos V, queda cumplida en la época de Lepanto. Enfriadas las ilusiones de los primeros evangelistas, pacificado el antagonismo entre ellos y los conquistadores, ya queda la humanidad subyugada del Nuevo Mundo en el papel de cristiandad inferior, de hija fea de Dios, providencialmente caisada con el católico poder hegemćnico de los españoles que tanto necesiifta su dote para la cruzada del Mediterráneo. VII.

(52) Acosta, op. cit., libros V, VI y VII, especialmente el capítulo final (XXVIII), del lib.

(53) Ibid. llb. V, donde con insistencla explica todo lo que en sus religiones se asemejan al cristlanismo como ardid de Satanás para "usurpar y hurtar para sí la honra y culto dcbido a Dios" (lib. V, cap. XXIV, in fine).

(54) Capítulo final de la obra.

(55) "Karl V. als Begründer des spanischen Imperiums", en Die politische Welt Karls V, Múchen, s. a., pp. 66-93. 